\title{
Carcinoma in Anorectal Fistulas of Crohn's Disease with Seton Drainage
}

\author{
Case Report and Review of the Literature
}

Yukihiko Tokunaga Hirokazu Sasaki Tohru Saito

Department of Surgery, Osaka North Japan Post Hospital, Osaka, Japan

Dear Sir,

For a long time, Crohn's disease (CD) was not recognized as being a premalignant lesion. In recent decades, however, the incidence of $\mathrm{CD}$ has continued to rise worldwide and reports of colorectal cancer (CRC) in patients with CD have been cited in the literature with an increasing frequency [1-4]. Patients with CD usually tend to develop a malignancy in the bypassed ileum or right colon. To date, however, few cases of CRC arising in anorectal and/or perineal fistula secondary to $\mathrm{CD}$ have been reported in the literature $[1,2]$.

\section{Case Report}

A 57-year-old woman with an 11-year history of CD was referred to our hospital for surgical treatment of perianal abscess and anorectal fistula. She had a history of small bowel resection due to perforation 11 years earlier, when she was diagnosed as having CD and had been well controlled with oral intake of mesalazine. She complained of recurrent purulent discharge in the perianal and buttock regions. The discharge had started about 1.5 years before, resulting in an anorectal fistula.

Laboratory studies showed normal bilirubin and liver enzymes. Her complete blood cell counts were normal except for leukocytosis. Carcinoembryonic antigen and CA19-9 were within normal limits. Computed tomography (CT) revealed an anal fistula in the superficial external sphincter without any tumor.
In December 2004, an anorectal fistula at the 11 o'clock position was treated with seton drainage. In January 2005, another fistula at the 5 o'clock position was also treated with seton drainage. The anus was stenotic, $<1.5 \mathrm{~cm}$ in diameter due to chronic anorectal inflammation and scarring. In October 2005, a granulation around the fistula enlarged with elastic hard contents. Biopsy revealed adenocarcinoma. $\mathrm{CT}$ and magnetic resonance imaging (MRI) showed a massive tumor around the anorectal fistula invading the muscle and the perineal space.

Abdominoperineal resection was performed with a combined resection of the posterior wall of the vagina due to the tumor invasion. Pathological findings showed a moderately differentiated adenocarcinoma in and around the fistula invading the surrounding tissue. Postoperatively, she received chemotherapy with UFT (tegafur and uracil). Her CD condition has remained stable without any signs of cancer recurrence so far 24 months since the radical operation.

\section{Discussion}

Though there is an increasing incidence of CRC not associated with anorectal fistula in patients with CD [3], few publications have been available concerning the incidence of cancer arising in the anorectal fistula of CD. Adenocarcinoma in chronic perineal fistulae secondary to CD was first reported in 1975 by Lightdale et al. [5] who presented a 50-year-old woman. Ky et al. [2] reported 7 cases of anorectal carcinoma associated with CD that could be related to anal fistula. To the best of our knowledge, review of the literature has showed 22 cases of carcinoma of anorectal or perineal fistula in patients with CD (table 1).

Based on the data in reports of CRC associated with CD [6], the median ages of diagnosis ranging from 46 to 55 years seem relatively earlier than the mean age of diagnosis of CRC in the general population. The majority of CD patients in whom CRC is diagnosed have had the disease for more than 10 years. Patients' characteristics considered as risk factors include longstanding CD for over 10 years, CD onset before the age of 30 years, and the presence of bypassed bowel segments or strictures. Patients' characteristics with cancer arising in the fistula of $\mathrm{CD}$ also range within these values.

Anorectal fistulas in $\mathrm{CD}$ are usually complex and longstanding, since the fistula arises from a deep ulcer due to CD, rather than so-called crypt glandular infection in ordinal anorectal fistulas [7]. Although the causative relationship between anorectal fistula and CD has yet to be determined, Traube et al. [4] stated that fistula might lead to carcinogenesis because of the constant mucosal regeneration. The epithelial regeneration and hyperplasia are predisposed to malignant change. Choi and Zelig [8] studied the clinicopathologic features of 80 patients with CRC compli-

\section{KARGER}

Fax +41613061234

E-Mail karger@karger.ch

www.karger.com (c) 2008 S. Karger AG, Basel

0012-2823/08/0771-0020\$24.50/0

Accessible online at:

www.karger.com/dig
Yukihiko Tokunaga, MD, PhD

Department of Surgery, Osaka North Japan Post Hospital

1-1-6 Nakazaki, Kita-ku, Osaka 530-8798 (Japan)

Tel. +8166361 2071, Fax +81663618324

E-Mail tokunagay@usay6.com 
Table 1. Carcinoma of anorectal or perineal fistula in patients with CD

\begin{tabular}{|c|c|c|c|c|c|c|}
\hline $\begin{array}{l}\text { Case/ } \\
\text { year }\end{array}$ & $\begin{array}{l}\text { Gender/ } \\
\text { age }\end{array}$ & $\begin{array}{l}\mathrm{CD} \\
\text { duration } \\
\text { years }\end{array}$ & Fistula type & $\begin{array}{l}\text { Fistula } \\
\text { duration } \\
\text { years }\end{array}$ & Pathology & Author \\
\hline $1 / 1980$ & $\mathrm{~F} / 45$ & 20 & Rectovaginal & NA & AdenoCA & Chaikhouni \\
\hline 2/1981 & $\mathrm{F} / 30$ & 17 & Rectovaginal & NA & AdenoCA & Chaikhouni \\
\hline $3 / 1985^{1}$ & $\mathrm{~F} / 27$ & 13 & Anorectal & NA & NA & Kato \\
\hline $4 / 1995^{1}$ & $\mathrm{~F} / 31$ & 8 & Rectovaginal & 15 & MucinCA & Furukawa \\
\hline $5 / 1998$ & $\mathrm{M} / 47$ & $>10$ & Anorectal & $3 / 4$ & SCC & Ky \\
\hline $6 / 1998$ & $\mathrm{M} / 38$ & $>20$ & Anorectal & $>10$ & SCC & $\mathrm{Ky}$ \\
\hline 7/1998 & $\mathrm{F} / 30$ & 8 & Anorectal & $>11$ & SCC & Ky \\
\hline $8 / 1998$ & $\mathrm{~F} / 59$ & $>20$ & Rectovaginal & $>10$ & AdenoCA & Ky \\
\hline $9 / 1998$ & $\mathrm{~F} / 47$ & $>20$ & Anorectal & $>5$ & AdenoCA & Ky \\
\hline $10 / 1998$ & $\mathrm{~F} / 31$ & 20 & Anorectal & $>5$ & SCC & Ky \\
\hline $11 / 1998$ & $\mathrm{M} / 75$ & 50 & Anorectal & 50 & AdenoCA & Ky \\
\hline $12 / 2001^{1}$ & $\mathrm{M} / 41$ & $>20$ & Anorectal & $>20$ & SignetCA & Kuwabara \\
\hline $13 / 2002^{1}$ & $\mathrm{~F} / 29$ & 20 & Anorectal & NA & MucinCA & Okamoto \\
\hline $14 / 2002^{1}$ & $\mathrm{~F} / 29$ & 17 & Anorectal & NA & MucinCA & Okamoto \\
\hline $15 / 2002^{1}$ & $\mathrm{M} / 39$ & 13 & Anorectal & NA & MucinCA & Okamoto \\
\hline $16 / 2002^{1}$ & $\mathrm{M} / 37$ & 20 & Anorectal & 20 & MucinCA & Fukazawa \\
\hline $17 / 2002^{1}$ & $\mathrm{M} / 40$ & 20 & Anorectal & 20 & MucinCA & Fukazawa \\
\hline $18 / 2003^{1}$ & $\mathrm{M} / 46$ & 31 & Anorectal & 31 & AdenoCA & Hashimoto \\
\hline $19 / 2003^{1}$ & $\mathrm{M} / 27$ & 5 & Anorectal & 3 & MucinCA & Furukawa \\
\hline $20 / 2005^{1}$ & $\mathrm{M} / 38$ & 18 & Anorectal & 24 & MucinCA & Mizushima \\
\hline $21 / 2005$ & $\mathrm{M} / 47$ & 15 & Anorectal & 15 & AdenoCA & Kazama \\
\hline $22 / 2006^{1}$ & $\mathrm{~F} / 40$ & 21 & Rectovaginal & 2 & MucinCA & Miyamoto \\
\hline $23 / 2007^{2}$ & $\mathrm{~F} / 52$ & 11 & Anorectal & 3 & AdenoCA & Present case \\
\hline
\end{tabular}

$\mathrm{CA}=$ Carcinoma $\mathrm{CD}=$ Crohn's disease Mucin = mucinous; $\mathrm{NA}=$ not available SCC $=$ squamous cell carcinoma.

${ }^{1}$ Case reported in the Japanese literature. ${ }^{2}$ Present case. cating CD or ulcerative colitis. They indicated that carcinomas complicating $\mathrm{CD}$ and ulcerative colitis have strikingly similar clinicopathologic features, and also suggested a common underlying process such as chronic inflammation.

In general, the clinical findings are of little help in establishing the diagnosis of malignancy in CD. Symptoms of chronic inflammatory disease may obscure clinical manifestations of occult malignancy. Sudden changes in clinical course, such as severe pain, hemorrhage, obstruction, and tumor growth, in patients with a longstanding CD should therefore raise suspicion. Patients with longstanding anorectal or perineal fistula may well warrant diagnostic evaluation including CT, MRI, and colon fiber with biopsy of the involved area with the hope of earlier detection and treatment of the malignancy.

\section{Acknowledgment}

Dr. Akio Kurokawa is acknowledged for advice in preparing the report.

\section{References}

1 Chaikhoumi A, Regueyra FI, Stevens JR: Adenocarcinoma in perineal fistula of Crohn's disease. Dis Colon Rectum 1981;24:639643.

2 Ky A, Sohn N, Weinstein MA, Korelitz BI: Carcinoma arising in anorectal fistulas of Crohn's disease. Dis Colon Rectum 1998;41: 992-996.

3 Jess T, Gamborg M, Matzen P, Munkholm P, Sorensen TL: Increased risk of intestinal cancer in Crohn's disease: a meta-analysis of population-based cohort studies. Am J Gastroentrol 2005;100:2724-2729.
4 Traube J, Simpson S, Riddell RH, Levin B, Kirsner JB: Crohn's disease and adenocarcinoma of the bowel. Dig Dis Sci 1980;25:939944.

5 Lightdale CJ, Sternberg SS, Posner G, Sherlock P: Carcinoma complicating Crohn's disease: report of seven cases and review of the literature. Am J Med 1975;59:262-268.

6 Nikias G, Eisner T, Katz S, Levin L, Eskries D, Urmacher C, McKinley M: Crohn's disease and colorectal carcinoma: rectal cancer complicating longstanding active perianal disease. Am J Gastroenterol 1995;90:216-219.

7 Okamoto K, Iwadare J, Kitamura N: A study of cancerization in patients with Crohn's disease. Stomach and intestine (I to Cho) 2002; 37:1023-1030.

8 Choi PM, Zelig MP: Similarity of colorectal cancer in Crohn's disease and ulcerative colitis: implication of carcinogenesis and prevention. Gut 1994;5:950-954. 